\title{
The influence of photochemistry on gravity waves in the middle atmosphere
}

\author{
Jiyao $\mathrm{Xu}$ \\ Laboratory of Numeric Study of Heliospheric Physics, Center for Space Science and Applied Research, \\ The Chinese Academy of Sciences, Beijing, China
}

(Received July 24, 1998; Revised January 27, 1999; Accepted June 1, 1999)

\begin{abstract}
This paper focuses on the effect of diabatic processes due to photochemical heating on long-period gravity waves in the stratosphere, mesosphere and lower thermosphere. A linear diabatic gravity wave model is established and compared to a model of pure dynamical adiabatic gravity waves. The results indicate that the photochemistry has a damping effect on gravity waves in most regions of the stratosphere and mesosphere. However, the photochemistry has a destabilizing effect on gravity waves in the mesopause region. The photochemical heating process can induce a comparatively strong enhancement of gravity waves at the mesopause for lower temperatures. In the summer polar mesopause region, this growth rate may be greater by about one order of magnitude than the growth rate of gravity waves at other seasons and locations.
\end{abstract}

\section{Introduction}

Gravity waves are one of the most common wave phenomena in the atmosphere. Gravity wave saturation and breaking have been recognized to play an essential role in the largescale circulation and chemical composition and energy budget in the middle atmosphere (e.g., Lindzen, 1981; Fritts, 1984; Garcia and Solomon, 1985; Lübken, 1997). One of decisive factors of wave saturation and breakdown is wave amplitude (Lindzen, 1981; Fritts, 1984). Thus, the study of the enhancement of wave amplitude during wave propagation is very important. It is common knowledge that gravity wave amplitudes grow exponentially with height due to the decrease in atmospheric density.

In the middle atmosphere, the fundamental processes include photochemical, dynamical and radiative processes. These processes are not independent, because the atmosphere is a highly interactive system characterized by non-linear coupling. Therefore, strictly speaking, any wave process in the middle atmosphere system will have chemical, thermal, and dynamical effects. Relatively little attention has been given to the effects of photochemistry on the propagation properties of gravity waves until now. A fundamental question has yet to be answered. Can the coupling among radiation, photochemistry, and dynamics results in the damping or enhancement of gravity waves?

Leovy (1966) firstly pointed out that photochemistry could damp or enhance gravity waves and photochemistry could cause gravity waves destabilization near the altitude of mesopause. The growth rate of gravity wave has a scale of about $3 \times 10^{-6} \mathrm{~s}^{-1}$. Owing to this small growth rate, this process has not been paid serious attention. Xun Zhu and Holton (1986) have investigated the damping effect of photochemistry on gravity waves in the stratosphere using a

Copy right (c) The Society of Geomagnetism and Earth, Planetary and Space Sciences (SGEPSS); The Seismological Society of Japan; The Volcanological Society of Japan; The Geodetic Society of Japan; The Japanese Society for Planetary Sciences. simple ozone photochemical model.

In recent years, many researchers (e.g., Harris and Adams, 1983; Brasseur and Offermann, 1986; McDade and Llewellyn, 1993; Mlynczak and Solomon, 1993; Riese et al., 1994; Meriwether and Mlynczak, 1995) proposed that the photochemical heating is one of the major heating source in the mesopause region. Therefore, it is plausible that the non-adiabatic process of photochemical heating could be important in the study of wave propagation in this region.

The purpose of this paper is to make an unitary gravity wave model in stratosphere, mesosphere and lower thermosphere considering the coupling between the photochemistry and the dynamics and use the latest knowledge about photochemical reactions and the associated heating to investigate the influence of photochemical processes on gravity waves in stratosphere, mesosphere and lower thermosphere. Xun Zhu and Holton (1986) considered the ozone continuity equation in their model. The effects of nitrogen, hydrogen and chlorine compounds were included by adjusting the pure oxygen destruction rate by an amplification factor $e$. The model in this paper considers all important photochemical reactions in the stratosphere, mesosphere and lower thermosphere. It includes the continuity equations of all major trace gases in this region. The results of this model are compared with the results from a pure dynamical adiabatic gravity wave. In Section 2, a model of gravity wave propagation which includes the diabatic effects of photochemistry is established. In addition, the method whereby the wave parameters, such as wave frequency and growth rate of the wave, are calculated is described. In Section 3, the calculated results are presented. For comparison, the growth rates of gravity waves are calculated for three circumstances: (1) gravity waves in pure dynamical adiabatic conditions, (2) gravity waves with the cooling process included and (3) gravity waves with the cooling and the heating processed simultaneously included. The damping effect of the photochemistry on gravity waves 
in the stratosphere is discussed. The enhancement effect of photochemistry on gravity waves in the mesopause region and its variation with temperature are described. Section 4 gives the conclusions.

\section{Model and Calculation Method}

Holton (1972) has given the pure dynamical linear inertia internal gravity wave equations in adiabatic condition. If the diabatic processes of photochemical heating and cooling are considered, the linear inertia internal gravity wave equations are as follows:

$$
\begin{aligned}
& \frac{\partial u^{\prime}}{\partial t}+\bar{u} \frac{\partial u^{\prime}}{\partial x}+\bar{v} \frac{\partial u^{\prime}}{\partial y}-f v^{\prime}+\frac{\partial \phi^{\prime}}{\partial x}=0, \\
& \frac{\partial v^{\prime}}{\partial t}+\bar{u} \frac{\partial v^{\prime}}{\partial x}+\bar{v} \frac{\partial v^{\prime}}{\partial y}+f u^{\prime}+\frac{\partial \phi^{\prime}}{\partial y}=0, \\
& \frac{\partial u^{\prime}}{\partial x}+\frac{\partial v^{\prime}}{\partial y}+\left(\frac{\partial}{\partial z}-\frac{1}{H}\right) w^{\prime}=0, \\
& \frac{\partial \phi_{z}^{\prime}}{\partial t}+\bar{u} \frac{\partial \phi_{z}^{\prime}}{\partial x}+\bar{v} \frac{\partial \phi_{z}^{\prime}}{\partial y}+N^{2} w^{\prime} \\
& =\frac{R}{H C_{\mathrm{p}}}\left(\frac{\partial Q_{0}}{\partial T_{0}} \frac{H}{R} \phi_{z}^{\prime}+\sum_{j=1}^{J} \frac{\partial Q_{0}}{\partial q_{j}^{0}} q_{j}^{0} q_{j}^{\prime}\right), \\
& \frac{\partial q_{i}^{\prime}}{\partial t}+\bar{u} \frac{\partial q_{i}^{\prime}}{\partial x}+\bar{v} \frac{\partial q_{i}^{\prime}}{\partial y}+w^{\prime} \frac{\partial \ln \left(q_{i}^{0}\right)}{\partial z} \\
& =\frac{1}{n_{i}^{0}}\left[\frac{\partial\left(P_{i}^{0}-L_{i}^{0}\right)}{\partial T_{0}} \frac{H}{R} \phi_{z}^{\prime}+\sum_{j=1}^{J} \frac{\partial\left(P_{i}^{0}-L_{i}^{0}\right)}{\partial q_{j}^{0}} q_{j}^{0} q_{j}^{\prime}\right], \\
& i=1,2,3, \ldots, J,
\end{aligned}
$$

where $\bar{u}$ and $\bar{v}$ are the background wind components in $x$ and $y$ direction respectively. $\phi$ is the geopotential. $n_{i}^{0}$, $(i=1,2, \ldots, J)$ are the densities of background trace gases. $q_{i}^{0},(i=1,2, \ldots, J)$ are the background trace gas mixing ratios. $f$ is the Coriolis parameter. $H$ is the scale height. $T_{0}=\frac{H}{R} \bar{\phi}_{z}=\frac{H}{R} \frac{\partial \bar{\phi}}{\partial z}$ is the background temperature. $N$ is the Brunt-Väisälä frequency. $C_{\mathrm{p}}$ is specific heat at constant pressure. $R$ is gas constant. $P_{i}$ and $L_{i}$ are the rates of photochemical production and loss for species $i$. Equation (5) is the photochemical reaction continuity equation for species $i$. Xun Zhu and Holton (1986) only considered the ozone continuity equation in their model. The effects of nitrogen, hydrogen and chlorine compounds were considered by adjusting the reaction rate of $\mathrm{O}+\mathrm{O}_{3}=2 \mathrm{O}_{2}$. This model considers all important photochemical reactions in the stratosphere, mesosphere and lower thermosphere. It includes the continuity equations of all major trace gases in this region. Therefore, the effects of nitrogen, hydrogen and chlorine compounds are considered automatically. In the calculation, oxygen compounds: $\left(\mathrm{O}_{3}, \mathrm{O}\left({ }^{3} \mathrm{P}\right), \mathrm{O}\left({ }^{1} \mathrm{D}\right)\right)$, hydrogen compounds: $\left(\mathrm{H}, \mathrm{OH}, \mathrm{HO}_{2}\right)$, nitrogen compounds: ( $\mathrm{N}, \mathrm{NO}$, $\left.\mathrm{NO}_{2}, \mathrm{NO}_{3}, \mathrm{~N}_{2} \mathrm{O}_{5}, \mathrm{HNO}_{3}\right)$ and chlorine compounds: $(\mathrm{Cl}$, $\mathrm{ClO}, \mathrm{HCl}, \mathrm{HOCl}$ ) are considered. So, $J=16 . u^{\prime}, v^{\prime}, w^{\prime}$ and $\phi^{\prime}$ are the perturbation of $u, v, w$ and $\phi$ respectively.
$q_{i}^{\prime}=\Delta q_{i} / q_{i}^{0}$ is the relative perturbation for species $i$. Here term $Q_{0}$ represent the net heating rate.

$$
Q_{0}=H_{0}-C_{0} .
$$

Heating rate $H_{0}$ includes solar heating, chemical reaction heating. $C_{0}$ is atmospheric infrared radiation cooling rate. The calculation method of solar heating and the heating due to the exothermic chemical reaction is the same as the method of Mlynczak and Solomon (1993). The atmospheric cooling rate $C_{0}$ is calculated using the code provided by Fomichev et al., (1996).

Assuming the existence of wave solutions of equations of the form

$$
\beta^{\prime}=\beta_{0}^{\prime} \exp \left(i \omega t-i(k x+l y+m z)+\frac{z}{2 H}\right),
$$

where $\beta^{\prime}$ presents any one fluctuation of $u, v, w, T$ and $q_{i}(i=1,2, \ldots, J) . \quad \beta_{0}^{\prime}$ is the corresponding amplitude parameter of the wave. $k, l$ and $m$ are wave numbers in $x, y$ and $z$ directions respectively. $\exp \left(\frac{z}{2 H}\right)$ expresses the exponential growth with height of gravity waves due to the decreasing atmospheric density. $\omega$ is frequency of wave. It can be complex. $\omega=\omega_{r}+i \omega_{i} .-\omega_{i}$ is defined as the growth rate of the wave. When $-\omega_{i}<0$, the wave decays with time. In this case, $\omega_{i}$ can also be defined as damping rate. If $-\omega_{i}>0$, the wave is enhanced. Therefore,

$$
\begin{aligned}
& \text { If } \quad-\omega_{i}<0, \quad \text { the wave is damped. } \\
& \text { If } \quad-\omega_{i}>0, \quad \text { the wave is enhanced. }
\end{aligned}
$$

Equation (6) is substituted into Eqs. (1)-(5). Equations (1)(5) become coupled equations which are composed of $J+4$ equations. After eliminating the $w_{0}^{\prime}$, the equations become

$$
i \omega \vec{y}=A \vec{y},
$$

where $A$ is a square matrix with dimension equal to $J+3=$ $19, \vec{y}$ is a vector which elements are $u_{0}^{\prime}, v_{0}^{\prime}, \phi_{0}^{\prime}$, and $q_{0 i}^{\prime}$ $(i=1,2, \ldots, J)$. Here $\omega=\omega_{r}+i \omega_{i}=\omega_{0 r}-k \bar{u}-l \bar{v}+i \omega_{i}$ is the Doppler shift frequency and $-\omega_{i}$ is the growth rate of wave. The unknown quantity $\omega$ of the coupled equations can be solved by calculating the eignvalues of matrix $A$.

\section{Results and Discussion}

For comparison, the discussions are made in three cases.

Case 1. The gravity wave in adiabatic conditions.

In this case, the coupling between the dynamics and the photochemistry is lost. Equation (4) becomes (Holton, 1972)

$$
\frac{\partial \phi_{z}^{\prime}}{\partial t}+\bar{u} \frac{\partial \phi_{z}^{\prime}}{\partial x}+\bar{v} \frac{\partial \phi_{z}^{\prime}}{\partial y}+N^{2} w^{\prime}=0 .
$$

From Eqs. (1)-(3) and Eq. (8), we can obtain the dispersion relation as follow:

$$
\begin{gathered}
\omega_{r}^{2}=f^{2}+\frac{N^{2}\left(k^{2}+l^{2}\right)}{m^{2}+\frac{1}{4 H^{2}}}, \\
\omega_{i}=0 .
\end{gathered}
$$

The dispersion relation (9) indicates that atmospheric gravity waves are dispersive waves. $\omega_{i}=0$ indicates that the growth rates of gravity waves are zero. Therefore, for adiabatic conditions, atmospheric gravity waves are stable. 

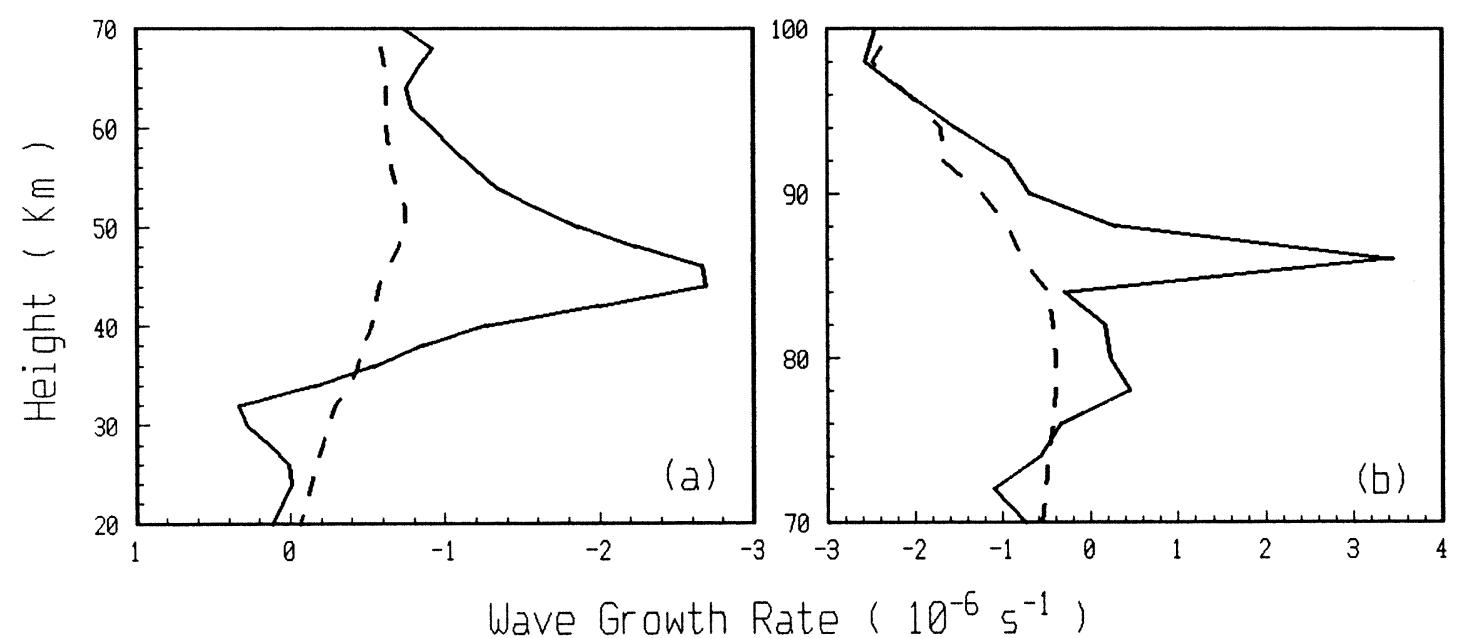

Fig. 1. The profiles of wave growth rate in stratosphere and lower mesosphere (a) and in upper mesosphere and lower thermosphere (b). The dashed line: the atmospheric cooling process is only considered. The solid line: the atmospheric cooling and heating processes are considered simultaneously.

\section{Case 2. The effect of cooling process on the gravity} wave.

In this case, the photochemical heating is not considered, therefore $H_{0}=0$. The net heating rate $Q_{0}=-C_{0}$. In order to obtain a simple analytical formula, the Newtonian cooling equation of the atmospheric cooling rate given by Dickinson (1973) is used in this case. Equation (4) can be revised as follows:

$$
\frac{\partial \phi_{z}^{\prime}}{\partial t}+\bar{u} \frac{\partial \phi_{z}^{\prime}}{\partial x}+\bar{v} \frac{\partial \phi_{z}^{\prime}}{\partial y}+N^{2} w^{\prime}=-\alpha \phi_{z}^{\prime}
$$

The dispersion relation derived from Eqs. (1)-(3) and Eq. (11) is

$$
\frac{\left(\omega^{2}-f^{2}\right)(\omega-i \alpha)}{\omega}=\frac{N^{2}\left(k^{2}+l^{2}\right)}{m^{2}+\frac{1}{4 H^{2}}},
$$

where $\alpha$ is the Newtonian cooling coefficient. (12) indicates that the wave frequency is complex.

When the wave frequency, $\omega \gg f$, from Eq. (12) we obtain

$$
\begin{gathered}
\omega_{r} \approx \sqrt{\frac{N^{2}\left(k^{2}+l^{2}\right)}{m^{2}+\frac{1}{4 H^{2}}}-\frac{\alpha^{2}}{4}}, \\
\omega_{i} \approx \frac{\alpha}{2}
\end{gathered}
$$

Expression (14) indicates that the atmospheric cooling process always damps atmospheric gravity waves. The damping rate is equal to half of Newtonian cooling coefficient.

\section{Case 3. The influence of cooling and photochemical} heating on the gravity wave.

If atmospheric cooling and photochemical heating processes are considered simultaneously, the gravity wave is described by Eqs. (1)-(5). The photochemical heating is calculated using similar method of Mlynczak and Solomon (1993). The atmospheric cooling rate is calculated using the code of Fomichev et al., (1996). The wave frequency $\omega_{r}$ and the wave growth rate $-\omega_{i}$ can be obtained by calculating the eignvalues of matrix $A$ in Eq. (7).
The rocket and radar data of Structure and Atmospheric Turbulence Environment (STATE) experiment, conducted during June 1983 at Poker Flat, Alaska, showed that there is a wide range of vertical wavelength $(2-30 \mathrm{~km})$ fluctuations near the summer mesopause. The horizontal wavelength is around $10^{3} \mathrm{~km}$ (Fritts et al., 1988). Therefore, as a representative example, the vertical wavelength and the horizontal wavelength are taken as $20 \mathrm{~km}$ and $1000 \mathrm{~km}$ for the calculations of the growth rate of the wave.

In the calculation, the background trace gas profiles are taken from the results of a one dimensional time dependent middle atmospheric photochemical model. The altitude range of the model is $10-150 \mathrm{~km}$. More than 100 photodissociations and chemical reactions are considered in this model. Photochemical reaction rate constants come from NASA report (DeMore et al., 1992). The main results of the model are similar to those of Allen's model (Allen et al., 1984). However, according to recent investigations (e.g., Allen, 1986; Clancy et al., 1987; Strobel et al., 1987; Allen and Delitsky, 1991) in the upper mesosphere and lower thermosphere, there is great discrepancy between models and observations of the oxygen compounds. In order to make the results realistic, in the calculation of the gravity wave growth rate, the background ozone and atomic oxygen profiles are taken from observational results (Thomas et al., 1983; Llewellyn et al., 1996).

The calculated results are shown in Fig. 1. The dashed line is the result when the atmospheric cooling process is the only process considered. The solid line shows the result when atmospheric cooling and heating processes are considered simultaneously. The U.S. Standard temperature profile is taken as the temperature in the calculation. The temperature at the mesopause is about $190 \mathrm{~K}$. Figure 1(a) indicates that in the range of $35-70 \mathrm{~km}$ photochemical reaction heating greatly increases the damping rate of the gravity wave. Comparing to the result where only atmospheric cooling is considered, the maximum increase is about a factor of three. This maximum occurs at an altitude of about $46 \mathrm{~km}$. The 

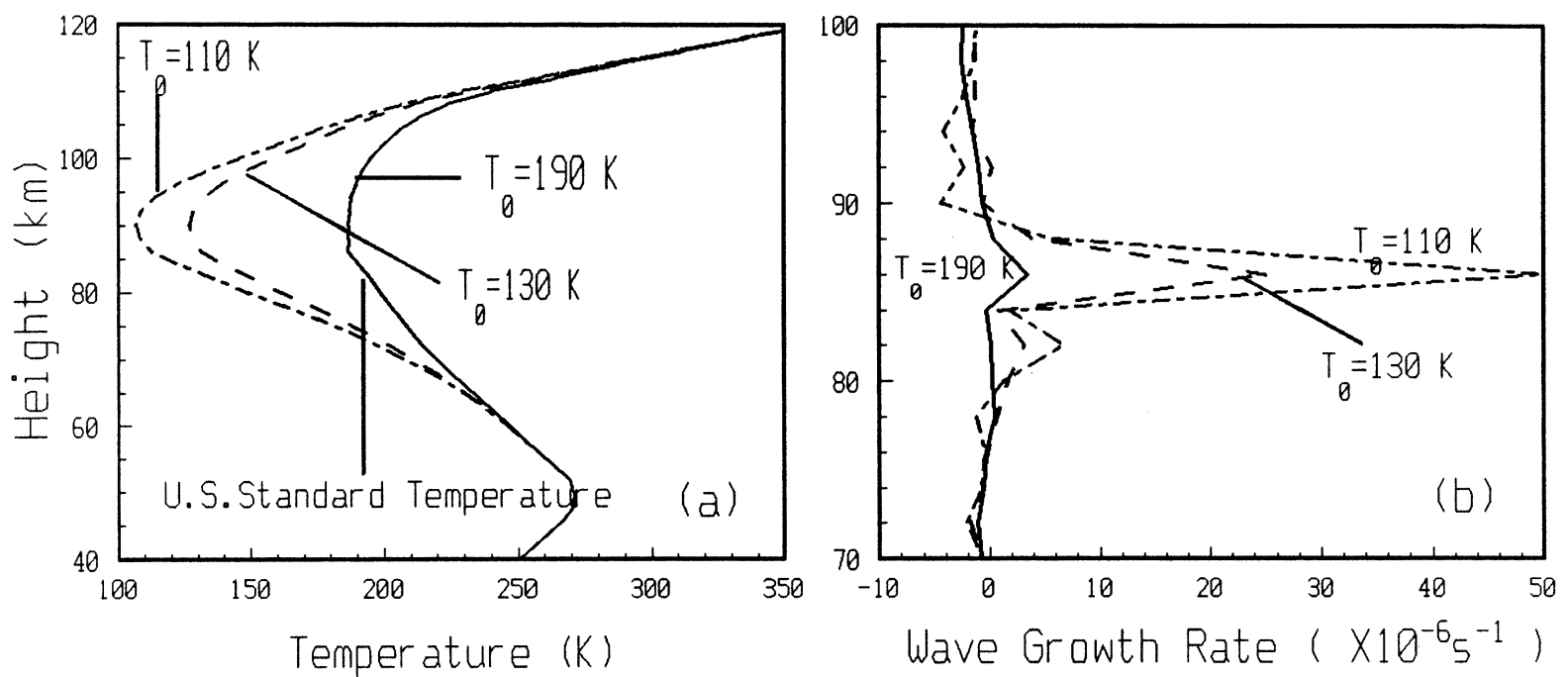

Fig. 2. (a) Three temperature profiles. The mesopause temperature $T_{0}$ (at $90 \mathrm{~km}$ ) is $110 \mathrm{~K}, 130 \mathrm{~K}$ and about $190 \mathrm{~K}$ (U.S. Standard temperature) respectively. (b) Wave growth rate $\left(\times 10^{-6} \mathrm{~s}^{-1}\right)$ profiles corresponding to the three temperature profiles.

damping rate is about $2.6 \times 10^{-6} \mathrm{~s}^{-1}$ or $0.22 \mathrm{day}^{-1}$. This result is very similar to that of Xun Zhu and Holton (1986).

In the stratosphere, the greatest heating photodissociation is the absorption of solar energy by ozone, $\mathrm{O}_{3}+h v=\mathrm{O}+\mathrm{O}_{2}$. Its heating rate at noon is about $17 \mathrm{~K} /$ day at the altitude of stratopause. The most important exothermic chemical reaction is $\mathrm{O}+\mathrm{O}_{2}+\mathrm{M}=\mathrm{O}_{3}+\mathrm{M}$. Its heating rate is about 6.3 $\mathrm{K} /$ day. The heating rate of above two photochemical reactions is about $94 \%$ of total heating rate near the stratopause at noon. Above $36 \mathrm{~km}, \frac{d q_{03}}{d z}<0$. According to the discussion of Xun Zhu and Holton (1986), the energy released by the ozone photodissociation will depress the gravity wave. The reaction rate constant of $\mathrm{O}+\mathrm{O}_{2}+\mathrm{M}=\mathrm{O}_{3}+\mathrm{M}$ is $6.0 \times 10^{-34}\left(\frac{300}{T}\right)^{2.3}$. The heating rate of this chemical reaction increases when temperature decreases. The temperature dependence of the exothermic chemical reaction rate depresses the wave amplitude as well. Thus the effects of both above two photochemical reactions are stabilizing. They have significant contributions to the damping rate of atmospheric gravity wave.

The damping rates for different wavelengths are calculated. The results indicate that there are not obvious changes of damping rate for different wavelengths. For examples, when the horizontal wavelength and vertical wavelength are $2000 \mathrm{~km}$ and $20 \mathrm{~km}$ respectively, the damping rate is about $2.4 \times 10^{-6} \mathrm{~s}^{-1}$. If the horizontal wavelength and vertical wavelength are $100 \mathrm{~km}$ and $5 \mathrm{~km}$ respectively, the damping rate is about $2.9 \times 10^{-6} \mathrm{~s}^{-1}$.

Figure 1(b) indicates that in the region of the mesopause, the photochemistry can induce the enhancement of a gravity wave. The reason for this behavior is that the mixing ratio of total odd oxygen increases with height near the mesopause region (Leovy, 1966). Similarly, since the mixing ratio of ozone increases with height in the lower stratosphere, relatively weak destabilized effect on waves occurs near $30 \mathrm{~km}$ (see Fig. 1(a)). For detail discussions about the effects of photochemical reactions on gravity waves, I refer the reader to Leovy (1966) and Xun Zhu and Holton (1986).

The largest seasonal variation in temperature occurs at the polar mesopause. Many observations indicate that the polar summer mesopause is the coldest region of the terrestrial atmosphere. The average temperature is about $130 \mathrm{~K}$ (Von Zahn and Meyer, 1989; Luebken, 1990), and a temperature below $100 \mathrm{~K}$ has recently been reported by Schmidlin (1992). The mesopause temperature increases from the summer pole to the winter pole where temperatures of the order of 210$220 \mathrm{~K}$ are typical. Since the photochemical reactions of importance in this region have strong temperature dependence, it is of interest to investigate the variation of gravity wave growth rate induced by photochemistry within this temperature range. For this investigation three temperature profiles are used. In the first case, the temperature profile of the U.S. Standard Atmosphere is used. The temperature at the mesopause is about $190 \mathrm{~K}$. The calculation indicates that the growth rate is about $3 \times 10^{-6} \mathrm{~s}^{-1}$. This result is similar to that of Leovy (1966). For the other two cases: the mesopause temperatures are $130 \mathrm{~K}$ and $110 \mathrm{~K}$ respectively. These temperature profiles are shown in Fig. 2(a). Figure 2(b) shows the gravity wave growth rate profiles in the upper mesosphere and lower thermosphere corresponding to these temperature profiles. The calculations indicate that the maximum growth rate are about $2 \times 10^{-5} \mathrm{~s}^{-1}$ and $5 \times 10^{-5} \mathrm{~s}^{-1}$ respectively. Therefore, the lower the temperature, the greater the wave growth rate in the mesopause region. The region of gravity wave enhancement induced by photochemistry is from 80 to $92 \mathrm{~km}$ and the region of maximum enhancement is at about $84-86 \mathrm{~km}$.

The major exothermic chemical reactions in the region of mesopause are shown in Table 1. From Table 1 we can see that the chemical heating is closely related to the density of atomic oxygen. In the region from $80 \mathrm{~km}$ to more than 90 $\mathrm{km}$, the mixing ratio of $\mathrm{O}\left({ }^{3} \mathrm{P}\right)$ increases with height. The photochemical heating rate is in proportion to the mixing ratio of $\mathrm{O}\left({ }^{3} \mathrm{P}\right)$. For downward motion, a descending par- 
Table 1. The important exothermic chemical reactions in mesopause region.

\begin{tabular}{lll}
\hline & \multicolumn{1}{c}{ Reaction } & Reaction rate constant \\
\hline $\mathrm{R} 1$ & $\mathrm{O}\left({ }^{3} \mathrm{P}\right)+\mathrm{O}\left({ }^{3} \mathrm{P}\right)+\mathrm{M}=\mathrm{O}_{2}+\mathrm{M}$ & $4.7 \times 10^{-33}\left(\frac{300}{T}\right)^{2.0}$ \\
$\mathrm{R} 2$ & $\mathrm{O}\left({ }^{3} \mathrm{P}\right)+\mathrm{O}_{2}+\mathrm{M}=\mathrm{O}_{3}+\mathrm{M}$ & $6.0 \times 10^{-34}\left(\frac{300}{T}\right)^{2.3}$ \\
$\mathrm{R} 3$ & $\mathrm{O}\left({ }^{3} \mathrm{P}\right)+\mathrm{OH}=\mathrm{O}_{2}+\mathrm{H}$ & $2.2 \times 10^{-11} \exp \left(\frac{120}{T}\right)$ \\
R4 & $\mathrm{H}+\mathrm{O}_{3}=\mathrm{OH}+\mathrm{O}_{2}$ & $1.4 \times 10^{-10} \exp \left(\frac{-470}{T}\right)$ \\
R5 & $\mathrm{HO}_{2}+\mathrm{O}\left({ }^{3} \mathrm{P}\right)=\mathrm{OH}+\mathrm{O}_{2}$ & $3.0 \times 10^{-11} \exp \left(\frac{200}{T}\right)$ \\
R6 & $\mathrm{H}+\mathrm{O}_{2}+\mathrm{M}=\mathrm{HO}_{2}+\mathrm{M}$ & $5.5 \times 10^{-32}\left(\frac{300}{T}\right)^{1.6}$ \\
\hline
\end{tabular}

${ }^{\star}$ Rate constants are in units of $\mathrm{cm}^{6} \mathrm{~s}^{-1}$ for termolecular reactions and $\mathrm{cm}^{3} \mathrm{~s}^{-1}$ for bimolecular reactions.

cel will contain more $\mathrm{O}\left({ }^{3} \mathrm{P}\right)$ than its surroundings and will be warmed diabatically. This process will produce a positive correlation between temperature and vertical velocity and increase gravity wave amplitude. The reaction rates in Table 1 increase when the background temperature decreases except for reaction $\mathrm{R} 4$. Therefore, when the background temperature decreases, the photochemical heating will increase. At the same time, the atmospheric cooling rate (caused by $\mathrm{CO}_{2}$, $\mathrm{H}_{2} \mathrm{O}$ and $\mathrm{O}_{3}$ etc.) will decrease, causing the net heating rate to further increase. Thus when the background temperature decreases, the destabilizing effect of photochemistry will be intensified and the growth of gravity waves will be rapid.

The amplifying effect of photochemistry on gravity wave amplitudes is related to the time $t_{0}$ which is taken by gravity waves propagating through the enhancement region in addition to growth rate $-\omega_{i}$. The vertical propagation speed of a gravity wave is its group speed $C_{\mathrm{g}}=\frac{\partial \omega}{\partial m} \cdot m$ is vertical wave number. Suppose the thickness of the enhancement region induced by photochemistry is $D$. Thus, $t_{0}=\frac{D}{C_{\mathrm{g}}}$. After passing through this enhancement region, amplitude of gravity wave is amplified by $\alpha_{\mathrm{P}}=\exp \left(\frac{-\omega_{i} D}{C_{\mathrm{g}}}\right) \cdot \alpha_{\mathrm{P}}$ is defined as amplifying factor caused by photochemistry. In addition, a gravity wave passing through this region from lower altitude will be also amplified due to the decreasing of atmospheric density. The amplifying factor due to the decreasing of atmospheric density is $\alpha_{\rho}=\exp \left(\frac{D}{2 H}\right)$. $H$ is the scale height. Thus, the total amplifying factor $\alpha$ of gravity wave passing through this region is

$$
\alpha=\alpha_{\mathrm{P}} \alpha_{\rho}=\exp \left(\frac{-\omega_{i} D}{C_{\mathrm{g}}}\right) \exp \left(\frac{D}{2 H}\right) .
$$

The amplifying factor caused by photochemistry $\alpha_{\mathrm{P}}$ of different vertical wavelengths for the altitude region of 84-86 $\mathrm{km}$ are calculated. In the calculation, $D$ is taken as $3 \mathrm{~km}$. Figure 3 gives the results of $\alpha_{\mathrm{P}}$ for three horizontal wavelengths of $500 \mathrm{~km}, 1000 \mathrm{~km}$ and $2000 \mathrm{~km}$. Figures 3(a) and (b) is for the mesopause temperature of $130 \mathrm{~K}$ and $110 \mathrm{~K}$ respectively. Figure 3 indicates that $\alpha_{\mathrm{P}}$ increases with the increase of horizontal wavelength. $\alpha_{\mathrm{P}}$ reaches a maximum in the vertical wavelength region of $8-12 \mathrm{~km}$. This is because that the longer the vertical wavelength and the shorter the horizontal wavelength, the faster the gravity wave speed and the shorter the $t_{0}$. For instances, when the mesopause
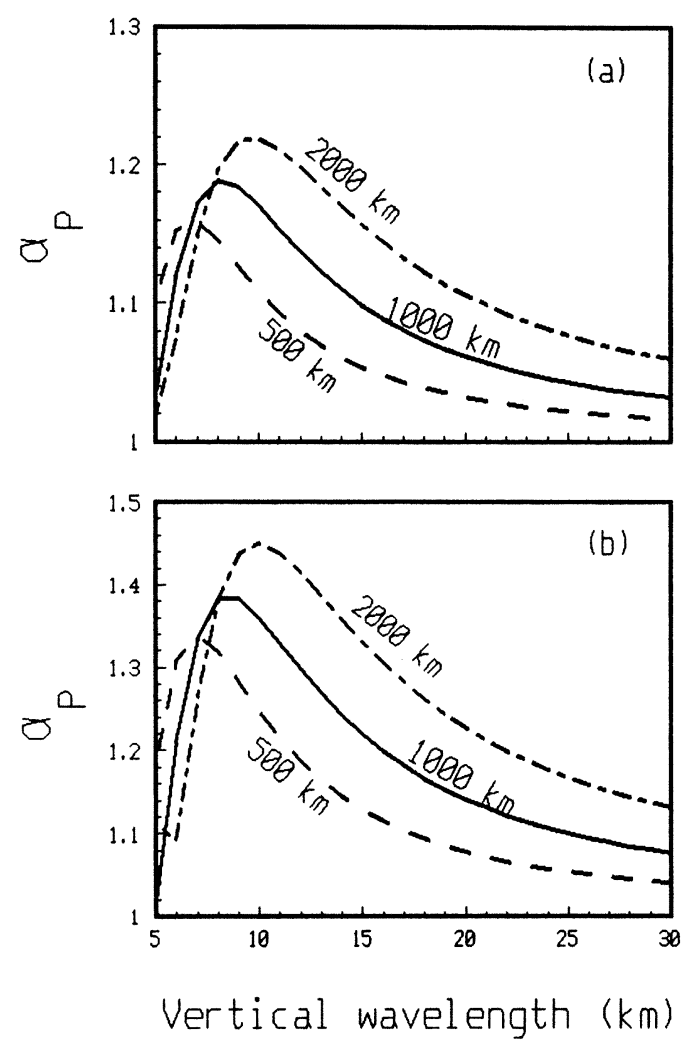

Fig. 3. The amplifying factors caused by photochemistry $\alpha_{\mathrm{P}}$ with variation of vertical wavelength for the altitude region of $84-86 \mathrm{~km}$ for horizontal wavelengths $(500 \mathrm{~km}, 1000 \mathrm{~km}$ and $2000 \mathrm{~km})$. (a) The temperature at mesopause is $130 \mathrm{~K}$. (b) The temperature at mesopause is $110 \mathrm{~K}$.

temperature is $130 \mathrm{~K}$, and when the horizontal wavelength and vertical wavelength are $1000 \mathrm{~km}$ and $10 \mathrm{~km}$ respectively, $t_{0}$ is about $1 \times 10^{4} \mathrm{~s}$. If the horizontal wavelength and vertical wavelength are $2000 \mathrm{~km}$ and $10 \mathrm{~km}$ respectively, $t_{0}$ is about $2.5 \times 10^{4} \mathrm{~s}$. In addition, if the vertical wavelength is very short, the growth rate $-\omega_{i}$ is very small. For examples, when the mesopause temperature is $130 \mathrm{~K}$ and the horizontal wavelength is $1000 \mathrm{~km}$, if the vertical wavelength is 20 $\mathrm{km}$, growth rate is about $25 \times 10^{-6} \mathrm{~s}^{-1}$. But if the vertical wavelength is $6 \mathrm{~km}$, the growth rate is only about $3.5 \times 10^{-6}$ $\mathrm{s}^{-1}$. Thus, $\alpha_{\mathrm{P}}$ has peaks in the vertical wavelength region of $8-12 \mathrm{~km}$. 
From Fig. 3 we can see that when the mesopause temperature is $130 \mathrm{~K}$, the maximum $\alpha_{\mathrm{P}}$ is about 1.2 . If the mesopause temperature is $110 \mathrm{~K}$, the maximum $\alpha_{\mathrm{P}}$ is about 1.4 . However, when the mesopause temperature is $190 \mathrm{~K}$, the maximum $\alpha_{\mathrm{P}}$ is only about 1.03 (this case is not shown in Fig. 3). For comparison, the amplifying factor due to the decreasing of atmospheric density $\alpha_{\rho}$ of the altitude region of $84-86 \mathrm{~km}$ is about 1.3. $\alpha_{\rho}$ has nothing to do with the wavelengths and frequency of gravity wave. Thus, when the mesopause temperature is low, the amplifying effect of photochemistry on gravity waves is comparable to the amplifying effect due to the decreasing of atmospheric density. Photochemistry will enhance the growth rate of gravity wave with height.

\section{Conclusion}

The gravity wave model which considers the effect of diabatic processes due to photochemical heating was established on the basis of the model of Xun Zhu and Holton (1986) in which the ozone continuity equation is considered. The model in this paper comprehensively considers the continuity equations of oxygen, nitrogen, hydrogen and chlorine compounds and all important photochemical reactions in the stratosphere, mesosphere and lower thermosphere.

A comparison between the adiabatic pure dynamical gravity wave and this diabatic gravity wave including photochemical processes indicates that the diabatic effect of the photochemistry indeed influences the propagation of the gravity wave.

In the stratosphere and lower mesosphere, photochemical reaction heating enhances the damping of gravity waves. However, the mesopause region is a special layer. In this region, the non-adiabatic process of photochemical heating cannot be neglected. These photochemical processes can produce gravity wave enhancement at the mesopause. Under the average conditions for which the mesopause temperature is about $190 \mathrm{~K}$, gravity waves are enhanced in this region. However, the growth rate of the wave for these conditions is very small as shown previously by Leovy (1966). This growth rate increases with decreasing temperature. Because the temperature at the polar mesopause decreases greatly in summer season, the growth rate is significantly increased. It is plausible that gravity wave may be enhanced by photochemistry in the region of about $84-86 \mathrm{~km}$ when the mesopause temperature is low. The amplifying effect of photochemistry on gravity waves is equivalent to the amplifying effect due to the decreasing of atmospheric density especially for vertical wavelength about $10 \mathrm{~km}$ and long horizontal wavelengths.

Reid et al., (1988) and Lübken et al., (1997) measured the gravity wave momentum fluxes and suggested that the most intense wave breaking occurs above $86 \mathrm{~km}$ in polar mesopause in summer. Several mechanisms for dynamical instability and breaking of gravity waves have been proposed and studied by many researchers (e.g., Lindzen, 1981; Balsley et al., 1983; Fritts, 1984; VanZandt and Fritts, 1989). Gravity wave amplification induced by photochemistry in mesopause region should be considered as an additional factor causing gravity wave breaking in the summer polar mesopause region.

On the other hand, the interaction between waves is very common in the actual atmosphere. The background field of a wave can be modulated by the other waves. Therefore, propagation of one wave can be influenced by the other waves. However, the present model has a limitation for studying this process because that the model is linear. This process of nonlinear interaction between waves is very worth further being studied.

Acknowledgments. The author thanks Prof. Fomichev for providing the code of atmospheric cooling rate and the help given by $\mathrm{Ms}$. Zhu Yu in preparation of this paper. He also thanks anonymous referees for constructive criticism and very good suggestions. This research was supported by project "Storm 23" of the Chinese Academy of Sci. and the National Science Foundation of China (49990454).

\section{References}

Allen, M., A new source of ozone in the terrestrial upper atmosphere?, $J$. Geophys. Res., 91, 2844-2848, 1986.

Allen, M. and M. L. Delitsky, A test of odd oxygen photochemistry using Spacelab 3 atmospheric trace molecule spectroscopy observations, $J$. Geophys. Res., 96, 12883-12891, 1991.

Allen, M., J. I. Lunine, and Y. I. Yung, The vertical distribution of ozone in the mesosphere and lower thermosphere, J. Geophys. Res., 89(D3), 4841-4872, 1984.

Balsley, B. B., W. L. Ecklund, and D. C. Fritts, VHF echoes from the high-latitude mesosphere and lower thermosphere: observations and interpretations, J. Atmos. Sci., 40, 2451-2466, 1983.

Brasseur, G. and D. Offermann, Recombination of atomic oxygen near the mesopause: interpretation of rocket data, J. Geophys. Res., 91, 1081810824, 1986.

Clancy, R. T., D. W. Rusch, R. J. Thomas, M. Allen, and R. S. Eckman, Model ozone photochemistry on the basis of solar mesosphere explorer mesospheric observations, J. Geophys. Res., 92, 3067-3080, 1987.

DeMore, W. B., C. J. Howard, S. P. Sander, A. R. Ravishankara, D. M. Golden, C. E. Kolb, R. F. Hampson, M. J. Molina, and M. J. Kurylo, Chemical kinetics and photochemical data for use in stratospheric modeling, Eval. 10, JPL Publ. 92-20, Jet Propul. Lab., Calif. Inst. of Tech., Pasadena, Calif., 1992.

Dickinson R. E., A method of parameterization of infrared cooling between altitudes of $30 \mathrm{~km}$ and $70 \mathrm{~km}$, J. Atmos. Sci., 78, 4451-4457, 1973.

Fomichev, V. I., W. E. Ward, and C. McLandress, Implications of variations in the $15 \mu \mathrm{m} \mathrm{CO}_{2}$ band cooling in the mesosphere and lower thermosphere associated with current climatologies of the atomic oxygen mixing ratio, J. Geophys. Res., 101(D2), 4041-4055, 1996.

Fritts, D. C., Gravit wave saturation in the middle atmosphere: a review of theory and observations, Reviews of Geophys. and Space Physics, 22, 275-308, 1984.

Fritts, D. C., S. A. Smith B. B. Balsley, and C. R. Philbrick, Evidence of gravity wave saturation and local turbulence production in the summer mesosphere and lower thermosphere during the STATE experiment, $J$. Geophys. Res., 93, 7015-7025, 1988.

Garcia, R. R. and S. Solomon, The effect of breaking gravity waves on the dynamical and chemical composition of the mesosphere and lower thermosphere, J. Geophys. Res., 90, 3850-3868, 1985.

Harris, R. D. and G. W. Adams, Where does the $\mathrm{O}\left({ }^{1} \mathrm{D}\right)$ energy go?, $J$. Geophys. Res., 88, 4918-4928, 1983.

Holton, J. R., An Introduction to Dynamic Meteorology, Chapter 9, pp. 161-183, Academic Press, Inc., 1972.

Leovy, C. B., Photochemical destabilization of gravity wave near the mesopause, J. Atmos. Sci., 23, 223-232, 1966.

Lindzen, R. S., Turbulence and stress owing to gravity wave and tidal breakdown, J. Geophys. Res., 86, 9707-9714, 1981.

Llewellyn, E. J. and I. C. McDade, A reference model for atomic oxygen in the terrestrial atmosphere, Adv. Space Res., 18(9/10), 209-226, 1996.

Lübken, F.-J., U. von Zahn, A. Manson, C. Meek, U.-P. Hoppe, F. J. Schmidlin, J. Stegmen, D. P. Murtagh, R. Ruster, G. Schmidt, H.-U. Widdel, and P. Espy, Mean state densities, temperatures and winds during the MAC.SINE and MAC/EPSILON campaigns, J. Atmos. Terr. Phys., 52(10/11), 955-970, 1990.

Lübken, F.-J., Seasonal variation of turbulent energy dissipation rates at high latitudes as determined by in situ measurements of neutral density fluctuations, J. Geophys. Res., 102(D12), 13441-13456, 1997. 
McDade, I. C. and E. J. Llewellyn, An assessment of the $\mathrm{H}+\mathrm{O}_{3}$ heating efficiencies in the night-time mesopause region, Ann. Geophysicae, 11, 47-51, 1993.

Meriwether, J. W. and M. G. Mlynczak, Is chemical heating a major cause of the mesosphere inversion layer?, J. Geophys. Res., 100(D1), 1379-1387, 1995.

Mlynczak, M. G. and S. Solomon, A detail evaluation of the heating efficiency in the middle atmosphere, J. Geophys. Res., 98(D6), 10517-10541, 1993.

Reid, I. M., R. Ruster, P. Czechowsky, and G. Schmidt, VHF radar measurements of momentum flux in the summer polar mesosphere over Andenes $\left(69^{\circ} \mathrm{N}, 16^{\circ} \mathrm{E}\right)$, Norway, Geophys. Res. Lett., 15, 1263-1266, 1988.

Riese, M., D. Offermann, and G. Brasseur, Energy released by recombination of atomic oxygen and related species at mesospause heights, $J$. Geophys. Res., 99, 14585-14594, 1994.

Schmidlin, F. J., First observation of mesopause temperature lower than 100 K, Geophys. Res. Lett., 19, 1643, 1992.
Strobel, D. F., M. E. Summers, R. M. Bevilacqua, M. T. Deland, and M. Allen, Vertical constituent transport in the mesosphere, J. Geophys. Res., 92, 6691-6698, 1987.

Thomas, R. J., C. A. Barth, G. J. Rottman, D. W. Rusch, G. H. mount, G. M. Lawrence, R. W. Sanders, G. E. Thomas, and L. E. Clements, ozone density in the mesosphere (50-90 km) measured by the SME near infrared spectrometer, Geophys. Res. Lett., 10, 245-248, 1983.

VanZandt, T. E. and D. C. Fritts, A theory of enhanced saturation of the gravity wave spectrum due to increases in atmospheric stability, Pure Appl. Geophys., 130, 399-420, 1989.

Von Zahn, U. and W. Meyer, Mesopause temperature in polar summer, $J$. Geophys. Res., 94(D12), 14647-14651, 1989.

Xun Zhu and J. R. Holton, Photochemical damping of inertio-gravity waves, J. Atmos. Sci., 43, 2578-2584, 1986.

J. Xu (e-mail: xjy@ns.lhp.ac.cn) 